\title{
EM BUSCA DA ORGANIZAÇÃO DEMOCRÁTICA: A TRAJETÓRIA DE RAMON MOREIRA GARCIA
}

\author{
Gustavo Luis Gutierrez \\ Unicamp \\ Maria Ester de Freitas \\ FGV-EAESP \\ Afrânio Mendes Catani \\ USP
}

\begin{abstract}
"Para nós, os seres humanos não são objeto; ou seja, controláveis por alguma mão invisível ou algum mecanismo, inatingível e auto-regulável, de ameaças. Para nós, o homem é um sujeito: um ser autodeterminado que é capaz de participar na transformação de seu mundo. Com sua capacidade

mos de sua inserção ampla no debate acadêmico e político.

Acreditamos que o resgate da obra de Garcia é conveniente e adequado, em função de sua relevância como trabalho de um intelectual atuante e original e também porque antecipa discussões que viriam a se tornar objeto de forte interesse anos depois dessa obra ser publicada.
\end{abstract} criadora, ele é capaz de transformar estreiteza em profundidade."

Ramon Moreira Garcia

Esta pensata tem como objetivo apresentar a obra do professor Ramon Moreira Garcia. Iremos tratar das principais idéias que esse original pensador defendeu e do referencial metodológico que adotou. Discutiremos também as implicações de suas idéias tanto na época em que foram escritas, de 1980 a 1992 , como nos dias de hoje.

Inicialmente, apresentaremos uma breve biografia do autor e desenvolveremos uma análise de seus trabalhos a partir de sua própria perspectiva de investigação, destacando seus principais temas de interesse, como a participação no trabalho, a ecologia e o planejamento organizacional. Em seguida, tratare-

\section{NOTAS BIOGRÁFICAS}

Carioca, formado em 1963 pela Escola Nacional de Agronomia ENA -, no Rio de Janeiro, Garcia desenvolveu uma trajetória acadêmica multidisciplinar. Concluiu, em 1969, sua especialização em Administração de Empresas e, em 1976, seu mestrado, com a dissertação in absencia "Introdução aos mecanismos de controle social nas organizações". Ambos os cursos foram realizados na FGV-EAESP. Iniciou em seguida um curso de mestrado em Administração Comparada e, logo após, um curso de doutorado na University of Southern California, sob a orientação do Professor Alberto Guerreiro Ramos, que não chegou a concluir, em função de problemas de saúde que o fizeram retornar ao Brasil. Pouco depois, enquanto realizava suas pesquisas de doutorado, recebeu a notícia da morte de Guerreiro Ramos, seu grande mestre.

Em 1971, inicia sua carreira na FGV-EAESP como professor do Departamento de Administração Geral e Recursos Humanos - ADM -, no qual ensinou Teoria das Organizações e Análise Comparativa das Organizações, além de coordenar seminários especiais sobre tecnologia apropriada e cooperativas para as turmas de graduação e pós-graduação. Foi chefe de departamento no biênio 1980-81 e participante ativo de seminários e congressos, como o Enanpad e os encontros da Sociedade Brasileira de Economias Rurais.

Garcia nunca rompeu com sua formação de base, o que é atestado por seu forte interesse por cooperativas, formas de trabalho associativo, uso apropriado de tecnologia, meio ambiente, ecologia e biotecnologia. Era dono de uma oratória apaixonada e veemente: um intelectual inquieto e inconformado com as regras burocráticas. Fervoroso defensor da "autonomia da emancipação", era visto por uns como um romântico idealista e, por outros, como talento provocador de gran- 
des reflexões. Faleceu em janeiro de 1995, durante suas férias no litoral do Rio Grande do Norte.

\section{PERSPECTIVA DE INVESTIGAÇÃo}

Entre 1980 e 1992, Ramon Moreira Garcia publicou seus textos regularmente na RAE - revista de administração de empresas - e na RAP - revista de administração pública-, além de desenvolver diversos relatórios de pesquisa, com apoio do Núcleo de Pesquisas e Publicações - NPP da FGV-EAESP. O conjunto dessa obra revela um intelectual inquieto, curioso, provocador, dotado de cultura singular, envolvido nas principais discussões contemporâneas das ciências humanas e, em particular, da Teoria das Organizações. A leitura desses textos permite perceber a emergência dos temas fundamentais de suas preocupações, bem como a crescente complexidade do referencial teórico utilizado.

Podem ser percebidos, com a ressalva de que esse tipo de classificação sempre implica um pouco de reducionismo e arbitrariedade, ao menos quatro grandes questões recorrentes em seus trabalhos, a saber: a) uma preocupação com a dimensão epistemológica do tratamento da participação e da autogestão; b) aspectos práticos da participação no trabalho e referentes à autogestão; c) ecologia e qualidade de vida; e d) indagações acerca do planejamento organizacional em empresas e na administração pública.

A questão metodológica, contudo, exige um tratamento especial. Alguns de seus artigos ilustram o referencial teórico por meio do qual aborda todos os temas (Garcia, 1980a; 1980b; 1984a; 1992b). A partir de uma leitura cuidadosa e sistemática das obras de Alberto Guerreiro Ramos e Paulo Freire, o pesquisador percebe a realidade como uma totalidade em que o sujeito social não somente é um produto de suas circunstâncias, porém, também, graças a seu engajamento crítico, um ativo criador dessas mesmas circunstâncias (Garcia, 1983, p. 122). A realidade, para Garcia, é uma totalidade articulada e dinâmica, cuja compreensão exige perceber a esfera do singular - as condições de vida do indivíduo, delimitado em suas circunstâncias -, que se relaciona dialeticamente com o particular - compreendido como o nível regional - e com o universal a comunidade humana.

Trata-se de um modelo complexo de interpretação das relações sociais, fundamentado na imagem de esferas concêntricas que se superpõem e se relacionam dialeticamente entre si. Dois aspectos são recorrentes na forma em que esse modelo é utilizado por Garcia: primeiro, a importância de destacar o aspecto concreto das condições de vida do sujeito social como ponto de partida para a análise sociológica e, segundo, a presença permanente da possibilidade de transformação e superação das condições dadas que envolvem o indivíduo, por meio de sua ação consciente. O modelo de Garcia representa uma sofisticação do paradigma organicista por meio da incorporação de características da Teoria dos Sistemas. Esse diálogo com a escola norte-americana foi desenvolvido por vários autores, entre os quais o mais famoso provavelmente tenha sido Jürgen Habermas.

A originalidade da leitura desenvolvida por Garcia, a partir de Guerreiro Ramos e Freire, reside no papel do aprendizado individual e organizacional. A idéia de emancipa- ção surge como uma possibilidade quase sem limites de reconstrução da identidade e das condições sociais e políticas em que o sujeito social se insere. Trata-se de uma revolução permanente, dialética no sentido amplo, porém sem depender de sínteses revolucionárias em grande escala, que desemboquem em transformações macroeconômicas, no sentido da tomada do Estado por um grupo específico. Justamente por isso deve-se partir das condições concretas de vida do indivíduo até compreender - e ilustrar - as relações mais amplas dessa singularidade com o particular e com o universal. E esse exercício intelectual só tem sentido se engajado no esforço de emancipação, ou seja, se apoiar a construção de condições mais dignas e conscientes de vida para todas as pessoas.

O modelo de Garcia constitui um modelo de interpretação das relações sociais, tanto do ponto de vista de sua lógica interna, como em relação à sua aplicabilidade para a compreensão de situações concretas específicas. Entretanto, deve-se fazer uma advertência: defender essa perspectiva nos anos 1980 é muito diferente de defendê-la hoje. $\mathrm{Na}$ época, a proposta foi duramente atacada: a partir de uma perspectiva conservadora, ela apresenta-se demasiadamente otimista, despertando dúvidas e incentivando uma postura crítica com relação à idéia de um ser humano basicamente materialista e preguiçoso; sob a ótica da esquerda ela é equivocada, porque não prega a revolução, conforme já fora ensinado por Marx e Engels. Além disso, é uma proposta perigosa, pois promove cisões dentro do movimento popular, o que poderia vir a ser capitalizado pelas forças conservadoras e reacionárias. Finalmente, a proposta foi qualificada 
como simplória, uma vez que se apóia em dois referenciais que o materialismo histórico considera falsos, infantis e superados: o organicismo e a teoria dos sistemas.

O fato de todos os textos de Garcia tratarem da participação nas organizações, da autogestão e da emancipação das pessoas por meio do aumento do esclarecimento e da autoconsciência - não só de si mesmo mas também das circunstâncias de vida - não foi suficiente para viabilizar um canal de diálogo efetivo com o campo da esquerda; ao contrário, constituía um elemento de conflito à medida que Garcia parecia se apropriar indevidamente de categorias de análise às quais não teria o direito de recorrer.

Deve-se ter presente que estamos nos referindo a um contexto fortemente politizado, que percebia uma metade do mundo contra a outra, em relação ao modelo econômico a ser adotado. Visto a partir dessa perspectiva, grande parte dos conflitos são compreensíveis e alguns até justificáveis. De fato, a crítica aos modelos que servem de base para o desenvolvimento do pensamento de Garcia não é totalmente infundada. Parte significativa dos textos sobre organizações que se fundamenta na Teoria dos Sistemas é bastante simplista. O próprio Garcia escreveu críticas arrasadoras nesse sentido. Quanto ao paradigma organicista, existe de fato toda uma literatura que o utiliza de forma bastante empobrecida. Deve-se também levar em conta o preconceito histórico da esquerda com relação à proposta.

Aqui, contudo, temos um dos aspectos mais curiosos presentes nos trabalhos de Garcia. Em artigo publicado em 1992, ele responde a essa crítica, invertendo a lógica da argumentação. A partir da leitura de um texto da década de 1930, de Ludwig
Von Bertalanffy, ele sustenta que o equilíbrio não é fruto de mecanismos de controle, mas sim da manutenção do desequilíbrio. Garcia defende que o equilíbrio é obtido por meio de interações dinâmicas e não pelo concurso de mecanismos especiais de controle. Por esse motivo, vamos encontrar inúmeras características, em qualquer sistema complexo, que resistem à usual atitude redutora do isolamento em partes separáveis, em variáveis autônomas e independentes, em particular os fenômenos relativos à adaptação e à evolução. Para as ciências naturais, segundo a leitura que faz de Bertalanffy, a vida não é manutenção ou restabelecimento do equilíbrio, mas essencialmente a manutenção do desequilíbrio (Garcia, 1992b, p. 166).

\section{FOCOS DE INVESTIGAÇÃO E REFLEXÃO}

Autogestão, ecologia e planejamento organizacional foram os temas focais de investigação de Garcia. Para o pesquisador, a autogestão é um processo amplo de transformação da organização, sempre apoiado em uma idéia de totalidade, no sentido da autodeterminação das pessoas. O objeto pesquisado são as cooperativas, entendendo que o projeto cooperativista - em seu sentido mais profundo - implica considerar seus integrantes como seres humanos autodeterminados, sujeitos ativos e conscientes, e portanto capazes de participar na transformação do mundo em que vivem (Garcia, 1988, p. 42). A passagem de uma organização cooperativa, no sentido tradicional, para essa que o autor percebe enquanto uma possibilidade, pode ser auxiliada pelo diagnóstico de emancipação, no qual os atores vão se descobrindo e descobrindo a realidade econômica e política que os rodeia; tal passagem é a denominada "travessia".

É importante destacar que Garcia antecipou várias práticas que depois seriam utilizadas pelas incubadoras tecnológicas de cooperativas, como o auxílio institucional de universidades e prefeituras, assim como a possibilidade de organização em redes como uma alternativa às relações hierárquicas e formalizadas. A idéia de rede seria trabalhada como um símile físico em que os elementos que a compõem estão relacionados entre si de maneira especial. Não existe apenas um “"nó" dominando os demais, mas cada "nó" está ligado aos demais por conexões múltiplas e variadas (Garcia, 1986, p. 73). O autor não percebe, contudo, a concepção de organização em rede de uma forma ingênua, e reconhece que o modelo de rede pode ser também usado para a realização de objetivos antidemocráticos ou repressivos. Daí a necessidade de promover não apenas a reestruturação dos componentes da rede ou a redefinição dos papéis institucionais a serem desempenhados, mas, sobretudo, tentar subordinar todo esse esforço de mudança à influência normativa de valores substantivos explícitos. Nesse sentido, os atributos democráticos de participação necessitam de um projeto ético (Garcia, 1986, p. 73).

Essa análise apresenta, ao menos, dois aspectos que devem ser destacados: o primeiro refere-se ao atributo normativo dos valores, o que significa que a organização autogerida necessita de regras internas para seu funcionamento. Regras democráticas e consensuais, bem entendido, mas sempre com um sentido normativo; ou seja, a autogestão não é percebida como resultante de 
processos voluntariosos ou espontâneos, mas decorre de um aprendizado coletivo, no sentido da autodeterminação. O segundo aspecto é a subordinação das regras aos valores substantivos de um projeto ético claramente definido. Essa posição incorpora, ou até mesmo antecipa, o tipo de relação que Habermas vai apontar como alternativa de ação política, ao sugerir uma intervenção que procure subordinar as determinações dos sistemas econômico e político a valores originais da dimensão social, que o filósofo denomina "mundo da vida". A mesma aproximação com a Teoria da Ação Comunicativa pode ser percebida na insistência de Ramon em valorizar a construção de consensos legítimos no interior das cooperativas (Garcia, 1984b, p. 121).

Um exemplo da complexidade do conceito de cooperativa que Garcia trabalhou pode ser encontrado quando, com o objetivo de preencher a lacuna que existe no campo da produção de tecnologias populares e comunitárias, define a missão de uma cooperativa de consumo como a de "promover a organização social dos consumidores, criando um 'espaço cultural' de aprendizado permanente sobre as coisas que dizem respeito à alimentação e à vida de modo geral" (Garcia, 1986, p. 46).

Com relação à ecologia e à qualidade de vida, Garcia elaborou uma síntese que surpreende pela simplicidade: ele incorpora a idéia de uma "nova riqueza", que deve levar em conta o bem-estar e a integridade do ser humano. A riqueza, portanto, teria de ser medida a partir de valores substantivos. Ele argumenta, por exemplo, que a produção e o consumo de refrigerantes, chicletes e tranqüilizantes representam significativa parcela da renda nacional da maioria dos países ditos desenvol- vidos. Entretanto, ele não reconhece qualquer critério de ordem substantiva que indique que um incremento do consumo desses itens possa ser aceito como índice de civilização (Garcia, 1987b, p. 32). Tal postura crítica não deve ser confundida com posições tradicionais do campo da esquerda marxista, porém algo articulado coerentemente no interior do modelo de interpretação da sociedade que o autor adota desde o início. Para Garcia, a transformação das "totalidades sociais" não se faz pela "superação" de um todo por outro - como entende que é o pensamento de Hegel -, porém pela reorganização dessa totalidade, que se torna capaz de articular as preexistentes em novo ordenamento: eis a chave de seu raciocínio, ou seja, as transformações ocorrem pela reorganização de totalidades complexas, diferenciadas e contraditórias (Garcia, 1987a, p. 19).

Garcia acreditava no aumento da importância do que ele chama de setor informal e alternativo da economia - que hoje chamaríamos de terceiro setor ou de economia social e solidária - e em sua capacidade de apontar novas formas de organização da produção. Não se eximia, porém, de temperar seu otimismo com algum pragmatismo, considerando que vivemos em uma época privilegiada, na qual se assiste ao desmoronamento de todas as ortodoxias e o grotesco e o sublime andam de mãos dadas (Garcia, 1987b, p. 36).

Em 1988, Garcia publicou um artigo no qual discutia o processo de planejamento estratégico. Tomou como exemplo a gestão de uma universidade e destacou a importância da elaboração de uma crítica institucional e de um exercício coletivo de criatividade, em linha com as propostas que surgiram originalmente nos textos sobre o diagnóstico de eman- cipação (Garcia, 1988). Em outro artigo, publicado alguns anos depois, aplicou essas mesmas concepções à questão da definição de políticas públicas, tomando o caso do orçamento da prefeitura de Campinas durante um período de 12 anos, de 1975 a 1987 (Garcia, 1992a).

Em "Acidentes em sistemas sociotécnicos de alto risco: uma proposta de 'planejamento institucional' para sistemas de energia elétrica" (Garcia, 1992b), apresentou um exemplo acabado do referencial metodológico que sempre defendeu: ele parte da situação concreta dos acidentes de trabalho no setor de produção de energia elétrica para discutir o papel conceitual do acidente no interior dos sistemas sociotécnicos e sua relação com os diversos paradigmas de pesquisa em ciências humanas, mostra a relatividade da importância da busca do equilíbrio em modelos de inspiração organicista e aponta para um novo paradigma no campo das ciências naturais.

\section{INTELECTUAL E SEU AMBIENTE}

Garcia teve uma trajetória de altos e baixos no mundo acadêmico. Fracassou seguidamente na tentativa de obter o grau de doutor, enfrentou problemas profissionais e de relacionamento nas diversas instituições em que trabalhou, além de dificuldades no sentido de estabelecer interlocutores em seu meio. Por outro lado, ao observar sua produção, percebemos que ela atende a todos os requisitos que definem um intelectual: reflete ampla cultura geral, domínio do referencial teórico e capacidade de dialogar com segurança com as demais escolas de pensamento. 
Garcia demonstrou, por meio de suas publicações, um esforço permanente e honesto de reflexão e atualização; acompanhou, e algumas vezes antecipou, temas que se tornaram em pouco tempo muito importantes, como as questões do terceiro setor, da ecologia e da qualidade de vida. Além disso, lutou para demonstrar as limitações do que ele acostumava chamar de paradigma mecânico-fatalista. Toda sua produção teórica vai se dar nos limites de um esforço por melhores condições de vida e de trabalho para as pessoas, o que ele identifica com o desenvolvimento e a disseminação de organizações democráticas, nas quais os membros possam atuar como seres humanos completos e utilizar toda a sua potencialidade criativa.

Ao lançarmos um olhar sobre a trajetória de Garcia, sobre as instituições em que ele atuou, e revermos as idéias que ele desenvolveu e defendeu, vemo-nos diante de algumas questões: o sistema acadêmico atual permite, incentiva e reconhece a criatividade e a inovação? Quanto a permitir, a resposta deve ser afirmativa, e o exemplo da trajetória de Garcia pode valer como argumento. Porém, as demais questões são de mais difícil resposta. Quem acompanhou a trajetória desse pensador pôde observar a busca, quase sempre frustrada, de interlocutores sinceros e desarmados para tentar discutir suas idéias. E, se em seu caso não houve incentivo, tampouco houve reconhecimento.

Felizmente, para seus leitores de ontem, de hoje e do futuro, independentemente da forma como seu meio o tratou, a questão fundamental que permeia todo seu trabalho intelectual - a necessidade de subordinar os requisitos organizacionais a valores humanos explicitamente articulados com um conjunto de princípios éticos - permanece atual e até mais urgente hoje do que quando foi escrita.

\section{REFERÊNCIAS E INDICAÇ̃̃ES BIBLIOGRÁFICAS}

GARCIA, R. M. A base de uma administração autodeterminada: o diagnóstico emancipador. RAE - revista de administração de empresas, v. 20, n. 2, p. 7-17, 1980a.

GARCIA, R. M. Abordagem sociotécnica: uma rápida avaliação. RAE - revista de administração de empresas, v. 20, n. 3, p. 71-77, 1980b.

GARCIA, R. M. Os requisitos de um programa de treinamento de cooperativas. RAE - revista de administração de empresas, v. 21, n. 1, p. 39-45, 1981.

GARCIA, R. M. A via de um guerreiro com sabedoria e senso de humor: uma sinopse da obra de Guerreiro Ramos. RAP - revista de administração pública, v. 17, n.1, p. 107-26, 1983.
GARCIA, R. M. Uma proposta alternativa de pesquisa: a investigação emancipadora. RAP - revista de administração pública, v. 18, n. 2, p. 144-59, 1984a.

GARCIA, R. M. Administração estratégica de cooperativas: cuidados especiais na organização e constituição de cooperativas de consumo. São Paulo: FGV-EAESP, 1984b. (Relatórios de pesquisa-NPP).

GARCIA, R. M. As redes institucionais de apoio e a produção local de alimentos. RAP - revista de administração pública, v. 20, n. 3, p. 70-80, 1986.

GARCIA, R. M. A "nova" riqueza e a gestão de recursos produtivos. RAE - revista de administração de empresas, v. 27, n. 2, p. 14-22, 1987a.

GARCIA, R. M. Tecnologia apropriada: amiga ou inimiga oculta? RAE - revista de administração de empresas, v. 27, n. 3, p. 26-38, 1987 b.

GARCIA, R. M. Enfrentando a crise: a prática da administração estratégica da Unibrás. RAP revista de administração pública, v. 22, n. 3, p. 111-130, 1988.

GARCIA, R. M. Contribuição à formação de políticas públicas relativas ao meio ambiente. São Paulo: FGV-EAESP, 1989. (Relatórios de pesquisa - NPP).

GARCIA, R. M. Administração estratégica de cooperativas: cuidados especiais na organização e constituição de cooperativas de consumo. São Paulo: FGV-EAESP, 1984b. (Relatório de pesquisa-NPP).

GARCIA, R. M. Contribuição à formulação de políticas públicas relativas ao meio ambiente. RAP - revista de administração pública, v. 26, n 3, p. 36-63, 1992a.

GARCIA, R. M. Acidentes em sistemas sociotécnicos de alto risco: uma proposta de "planejamento institucional" para sistemas de energia elétrica. RAP - revista de administração pública, v. 26, n. 4, p. 161-91, 1992b.

\title{
Pensata convidada. Aprovada em 08.03.04
}

\section{Gustavo Luis Gutierrez}

Professor no Departamento de Estudos do Lazer da Faculdade de Educação Física da Unicamp.

E-mail: gutierrez@fef.unicamp.br

\section{Maria Ester de Freitas}

Professora no Departamento de Administração Geral e Recursos Humanos da FGV-EAESP.

E-mail: mfreitas@fgvsp.br

\author{
Afrânio Mendes Catani \\ Professor no Departamento de Administração Escolar e Economia da Educação da Faculdade de Educação da USP. \\ E-mail: amcatani@usp.br
}

